\title{
Inhibition of CD147 expression by RNA interference reduces proliferation, invasion and increases chemosensitivity in cancer stem cell-like HT-29 cells
}

\author{
JIE CHEN ${ }^{1,2^{*}}$, YUQIN PAN ${ }^{2 *}$, BANGSHUN HE ${ }^{2}$, HOUQUN YING ${ }^{2,3}$, FENG WANG ${ }^{2}$, HUILING SUN $^{1,2}$, \\ QIWEN DENG ${ }^{2}$, XIAN LIU ${ }^{2}$, KANG LIN ${ }^{2}$, HONGXIN PENG ${ }^{2,3}$, WILLIAM C. CHO ${ }^{4}$ and SHUKUI WANG ${ }^{2}$ \\ ${ }^{1}$ Department of Life Sciences, Nanjing Normal University; ${ }^{2}$ Central Laboratory, Nanjing First Hospital, \\ Nanjing Medical University; ${ }^{3}$ Medical College, Southeast University, Nanjing, Jiangsu; \\ ${ }^{4}$ Department of Clinical Oncology, Queen Elizabeth Hospital, Kowloon, Hong Kong, P.R. China
}

Received June 9, 2015; Accepted July 20, 2015

DOI: 10.3892/ijo.2015.3138

\begin{abstract}
The association between CD147 and cancer stem cells (CSCs) provides a new angle for cancer treatments. The aim of this study was to investigate the biological roles of CD147 in colorectal CSCs. The Oct4-green fluorescent protein (GFP) vector was used to isolate CSCs and pYr-mir30-shRNA was used to generate short hairpin RNA (shRNA) specifically for CD147. After RNA interference (RNAi), CD147 was evaluated by reverse transcription-quantitative PCR and western blot analysis, and its biological functions were assessed by MTT and invasion assays. The results showed that the differentiation of isolated CSC-like HT-29 cells was blocked and these cells were highly positive for CD44 and CD147. RNAi-mediated CD147 silencing reduced the expression of CD147 at both mRNA and protein levels. Moreover, the activities of proliferation and invasion were decreased obviously in CSCs. Knockdown of CD147 increased the chemosensitivity of CSC-like cells to gemcitabine, cisplatin, docetaxel at $0.1,1$ and $10 \mu \mathrm{M}$ respectively, however, there was no significant difference among the three groups to paclitaxel at $10 \mu \mathrm{M}$. In conclusion, these results suggest that $\mathrm{CD} 147$ plays an important role in colorectal CSCs and might be regarded as a novel CSC-specific targeted strategy against colorectal cancer.
\end{abstract}

Correspondence to: Professor Shukui Wang, Central Laboratory of Nanjing First Hospital, Nanjing Medical University, 68 Changle Road, Nanjing, Jiangsu 210006, P.R. China

E-mail: shukwang@163.com

${ }^{*}$ Contributed equally

Key words: CD147, cancer stem cell, colorectal cancer, RNA interference, chemosensitivity

\section{Introduction}

Colorectal cancer, one of the three most common malignancies in the world, remains a major public health problem (1). In 2014, an estimated 71,830 men and 65,000 women were diagnosed with colorectal cancer and 26,270 men and 24,040 women will die of the disease (2). In recent years, remarkable advances have been made in colorectal cancer therapeutic approaches by using chemotherapy, radiotherapy, monoclonal antibodies and small-molecule inhibitors. However, the clinical outcome was far from expected as the effects of these improvements never continued for a long duration $(3,4)$. Therefore, new and better therapies will be the key to reducing the incidence of colorectal cancer.

A new emerging concept implicates that treatment failure occurs due to the existence of cancer stem cells (CSCs) that evade the treatment regimen $(5,6)$. These cells had been characterized by pluripotency, self-renewal as well as tumorigenicity (7-9). CSCs were resistant to traditional therapies, leading to tumor recurrence and unpleasant prognosis for cancer patients $(10,11)$. Conventional treatments mainly targeted the tumor cells, but not the CSCs. Thus, therapeutic strategies specifically targeting CSCs could eradicate colorectal cancer more effectively.

CSCs were firstly identified in hematopoietic tumors by using cell surface and intracellular molecules (12). Also other types of tumors have been examined for CSCs (13-16). Many studies had chosen specific cell surface markers such as CD19, CD20, CD24, CD44 and CD133 to characterize the subpopulation of CSCs. Transcription factor Oct 4 was also typically an intracellular marker (7,17-19). Oct4 (also known as OCT3, OCT3/4) belongs to the POU (Pit-Oct-Unc) family of transcription factors. It can form a complex binding to target genes in a sequence-specific manner and is involved in the signal regulation of stem cells $(20,21)$.

CD147 (also called EMMPRIN or basigin) is a transmembrane glycoprotein which was initially discovered on the surface of human cancer cells (22). Hao et al found both CD147 and CD44 were involved in prostate cancer invasion and played significant roles in drug resistance (23). Upregulation of CD147 was shown to accelerate invasion in vitro and 
tumorigenicity in nude mice (24). In addition, CD147 silencing in lung cancer epithelial cells inhibited Wnt/ $\beta$-catenin signaling and cell anchorage-independent growth (25). Our research group previously found CD147 was associated with colorectal tumor development in vitro and in vivo. Therefore we sought to explore the biological functions of CD147 in colorectal CSCs. To determine the potential roles of CD147 in $\mathrm{CSCs}$, the study was conducted by measuring the expression pattern of CD147 in CSC-like HT-29 cells and investigating its functions by assessment of proliferation, invasion and chemosensitivity of CSCs with CD147 knockdown.

\section{Materials and methods}

Cell culture. Human colorectal cancer cells HT-29 were obtained from Shanghai Cell Collection, the Chinese Academy of Science. The cells were maintained in DMEM (Hyclone, UT, USA) containing 10\% fetal bovine serum (FBS, Hyclone) and cultured at $37^{\circ} \mathrm{C}$ in a humidified atmosphere with $5 \% \mathrm{CO}_{2}$.

Construction of Oct4-green fluorescent protein (GFP) vector. The human Oct4 promoter (from 67,539 to 71,490 in human DNA sequence with accession number BA000025) was cloned into TOPO vectors and bi-directional sequencing was used to confirm the fidelity of the DNA sequence as previously described (26). Finally, the correct Oct4 promoter was cloned into the HindIII and $A g l$ sites of pEGFP-1 vector. The vector of pEGFP-1 included the GFP gene sequence, so the GFP expression can reflect the Oct4 promoter expression.

Transfection of cells and generation of stable cell clones. HT-29 cells were plated in 6-well plates at a density of $3 \times 10^{5}$ cells per well. When the cells reached $70-80 \%$ confluence, they were transfected with Oct4-GFP vector using Lipofectamine 2000 (Invitrogen Life Technologies, CA, USA) according to the manufacturer's instructions. Forty-eight hours after transfection, cells were routinely passaged at a 1:10 dilution and neomycin resistance clones were selected in the medium containing $0.8 \mathrm{mg} / \mathrm{ml} \mathrm{G} 418$ (Gibco, NY, USA). The survived clones were picked individually to 24-well plates and expanded to establish cell lines with $0.5 \mathrm{mg} / \mathrm{ml} \mathrm{G} 418$.

Isolation of $\mathrm{GFP}^{+}$cells. According to Rothermund et al (27), G418-resistant cells obtained from transfection were pooled and sorted with a Becton-Dickinson FACS Vantage SE flow cytometer equipped with the FACS DiVa Option and CellQuest software. The cytometer was equipped with an Innova Enterprise Laser (Coherent, CA, USA). Cells were excited at $488 \mathrm{~nm}$ and GFP signals were collected on the FITC detector with a 530/30 bandpass filter. Sorting gates were first drawn around FSC and SSC populations to remove dead cells and debris. A subsequent gate was set on GFP-positive cells. $\mathrm{GFP}^{+}$and GFP- cells were then sorted and analyzed with the flow cytometry. Subsequently, $\mathrm{GFP}^{+}$cells were expanded in the growth medium containing $0.5 \mathrm{mg} / \mathrm{ml} \mathrm{G} 418$.

CD44 and CD147 staining. Conjugated antibodies were carefully chosen to accommodate laser and detector configurations and to avoid the need to troubleshoot color compensation for antibody combinations. The following antibodies were used for a Becton-Dickinson FACS Canto ${ }^{\mathrm{TM}}$ II flow cytometer (BD Bioscience, CA, USA): allophycocyanin labeled monoclonal antibody against CD44 (CD44-APC, mouse anti-human IgG1, Biolegend, CA, USA) and fluorescein isothiocyanate labeled monoclonal antibody against CD147 (CD147-FITC, mouse anti-human IgG1, Biolegend). Monolayer cells were detached from culture plates with $0.25 \%$ trypsin (Gibco). Cells were then added into EP tubes and staining was performed using conditions recommended by the supplier. Quantitative evaluation of staining was performed with the filter settings of 520/550-FITC and 670/830-APC.

Construction of shRNA expression vectors specific for CD147 and incorporation into adenovirus. The vector pYr-mir30shRNA was used to generate short hairpin RNA (shRNA) specific for CD147 by selecting the 808-828 fragment as RNA interference (RNAi) target sites, and the oligonucleotides encoding a non-specific shRNA are shown in Table I. These oligonucleotides were annealed and subcloned into the $B s a \mathrm{I}$ sites of the vector according to the manufacturer's instructions. These recombinant vectors were designated as pYr-mir30-shRNA and pYr-mir30-shRNA-control, respectively. They were confirmed by DNA sequencing for correct ligation. Then plasmids carrying the target gene were transfected into HEK-293 cells together with adenoviral vector using Lipofectamine 2000 (Invitrogen Life Technologies). The growth medium was changed after $6 \mathrm{~h}$ and the cytopathic effect was observed periodically. When majority of the pathologically abnormal cells came off the bottom of the culture flask, the cells and supernatant were collected, frozen and thawed at $-80 / 37^{\circ} \mathrm{C}$ three times and cells were centrifuged at $1,220 \mathrm{x} g$ for $15 \mathrm{~min}$. Then the supernatant collected. With these procedures, two sets of adenoviruses were obtained: Ad-shRNA and Ad-shRNA-control.

Virus infection to inhibit CD147 gene expression. Isolated colorectal CSCs were seeded in 6-well plates at a density of $3 \times 10^{5}$ cells per well. When the cells reached $70-80 \%$ confluence, they were incubated with Ad-shRNA and Ad-shRNA-control [10 plaque forming units (10 PFU)/cell] in serum-free DMEM at $37^{\circ} \mathrm{C}$ for $4 \mathrm{~h}$, respectively. After incubation, serum-free DMEM was replaced with growth medium containing $0.5 \mathrm{mg} / \mathrm{ml} \mathrm{G} 418$. The infected cells were maintained at $37^{\circ} \mathrm{C}$ for another $48 \mathrm{~h}$.

RNA extraction, RT-PCR and reverse transcription-quantitative $P C R$. Gene expression was analyzed after extraction of cellular RNA from CSCs and infected cells with TRIzol reagent (Invitrogen) according to the manufacturer's instructions. Total RNA was reverse transcribed into cDNA using the PrimeScript RT reagent kit with gDNA Eraser (Takara, Osaka, Japan). CD147 and $\beta$-actin mRNA levels were analyzed by reverse transcription-quantitative polymerase chain reaction (RT-qPCR) with SYBR Premix Ex Tag ${ }^{\text {TM }}$ II (Takara) under conditions described by the supplier. cDNA $(2 \mu \mathrm{l})$ was in a final volume of $20 \mu \mathrm{l}$. The primer sequences were listed below. CD147 forward primer: 5'-CCATGCTGGTCTGCAAGTCAG-3', and reverse primer: 5'-CCGTTCATGAGGGCCTTGTC-3'; $\beta$-actin forward primer: 5'-CTGGAACGGTGAAGGTGACA-3', and reverse primer: 5'-AAGGGACTTCCTGTAACAACGCA-3'. The cycling program was $95^{\circ} \mathrm{C}$ for $30 \mathrm{sec}$, then followed by 40 cycles at $95^{\circ} \mathrm{C}$ for $5 \mathrm{sec}, 60^{\circ} \mathrm{C}$ for $30 \mathrm{sec}$, finally $95^{\circ} \mathrm{C}$ 
Table I. Sequences of the CD147-specific shRNAs.

\begin{tabular}{ll}
\hline shRNAs & \multicolumn{1}{c}{ Sequence } \\
\hline shRNA & 5'-GATCCGTGACAAAGGCAAGAACGTCTTCAAGA-3' \\
shRNA & 5'-GAGACGTTCTTGCCTTTGTCATTTTTGGAAA-3' \\
& 5'-AGCTTTTCCAAAAAATGACAAAGGCAAGAACG-3' \\
shRNA-control & 5'-TCTCTCTTGAAGACGTTCTTGCCTTTGTCACG-3' \\
& 5'-GATCCACTACCGTTGTTATAGGTGTTCAAGAGA-3' \\
shRNA-control & 5'-CACCTATAACAACGGTAGTTTTTTGGAAA-3' \\
& 5'-AGCTTTCCAAAAAAACTACCGTTGTTATAGGT-3' \\
& 5'-GTCTCTTGAACACCTATAACAACGGTAGTG-3' \\
\hline
\end{tabular}

for $15 \mathrm{sec}, 60^{\circ} \mathrm{C}$ for $1 \mathrm{~min}$. Calculated $\mathrm{Ct}$ values for CD147 mRNA were normalized to those obtained for the internal gene $\beta$-actin, $\Delta \mathrm{Ct}=\mathrm{Ct}_{\mathrm{CD} 147}-\mathrm{Ct}_{\beta \text {-actin }}$ and the $2^{-\Delta \Delta \mathrm{Ct}}$ methods were used to evaluate CD147 expression change. RT-qPCR was performed by ABI 7500 Real-Time PCR system (Applied Biosystems). Each sample was conducted in triplicate and all reactions were repeated three times.

Western blot analysis. Cells in logarithmic phase were harvested in lysis buffer $(50 \mathrm{mmol} / \mathrm{l}$ Tris-HCl, $\mathrm{pH} 7.4,150 \mathrm{mmol} / \mathrm{l} \mathrm{NaCl}$, $1 \mathrm{mmol} / 1 \mathrm{MgCl}_{2}, 100 \mathrm{mg} / \mathrm{ml}$ phenylmethanesulphonyl fluoride and $1 \%$ Triton $\mathrm{X}-100$ ) for $30 \mathrm{~min}$ on ice. Equal amounts $(30 \mu \mathrm{g})$ of lysate proteins were separated on 10\% SDS-PAGE gels and transblotted onto polyvinylidene difluoride (PVDF) membrane (Pall Corp., NY, USA). Non-specific-binding sites were blocked by washing blots in $5 \%$ non-fat dry milk in TBST buffer (10 mM Tris- $\mathrm{mCl}, \mathrm{pH} 7.5,150 \mathrm{mM} \mathrm{NaCl}$, and $1 \%$ Tween-20) for $2 \mathrm{~h}$ at room temperature with shaking. Then the membranes were immunoblotted with either mouse anti-human CD147 primary antibodies (1:500, Santa Cruz Biotechnology, Inc., Santa Cruz, CA, USA) or anti-human $\beta$-actin primary antibodies (1:500, Santa Cruz Biotechnology Inc.) overnight at $4^{\circ} \mathrm{C}$, washed in TBST and incubated with horseradish peroxidase conjugated secondary antibody (goat anti-mouse, 1:2,000, Santa Cruz Biotechnology Inc.) for $2 \mathrm{~h}$ at room temperature. Protein bands were detected using ECL detection system (Boster, Wuhan, China). Each analysis was performed at least three times.

Cell proliferation assay. The 3-(4,5-dimethylthiazol-2-yl)-2, 5-diphenyltetrazolium bromide (MTT) assay was used to assess the proliferation of infected cells. After infection for $48 \mathrm{~h}, 5 \times 10^{3}$ cells per well of each group were plated in 96-well plates. After $24,48,72$ and $96 \mathrm{~h}$ of culture, respectively, $20 \mu \mathrm{l}$ MTT $(5 \mathrm{mg} / \mathrm{ml})$ was added to each well and the plates were returned to incubator for another $4 \mathrm{~h}$. Then the medium was removed and $150 \mu \mathrm{l}$ of dimethylsulfoxide was added to each well. Ten minutes later, spectrometric absorbance at $490 \mathrm{~nm}$ was measured with a mircoplate reader. Each group was done in triplicate and repeated three times.

Invasion assay. The upper chamber of transwell plates $(8 \mu \mathrm{m}$ diameters, Corning Costar, USA) was coated with basement membrane Matrigel (20 mg/ml, Becton-Dickinson). After the Matrigel solidified at $37^{\circ} \mathrm{C}$, each group of cells $\left(1 \times 10^{5}\right)$ in $200 \mu \mathrm{l}$ serum-free DMEM were added to the upper chambers and the lower chambers were filled with $500 \mu$ l DMEM containing $10 \%$ FBS. After incubation at $37^{\circ} \mathrm{C}$ for $24 \mathrm{~h}$, cells were fixed with $100 \%$ methanol and then stained with $0.1 \%$ crystal violet for $10 \mathrm{~min}$. Cells that invaded the Matrigel and reached the lower surface of the chambers were counted in five random fields at x200 magnification under a light microscope, and the results were expressed as mean of five fields. The assay was performed in triplicate and repeated three times.

Drug sensitivity assay. To assess the chemosensivity after infection, cells were seeded in 96-well plates at a density of $1 \times 10^{4}$ cells per well and incubated for $24 \mathrm{~h}$. The medium was then removed and added with $200 \mu \mathrm{l}$ medium containing gemcitabine, cisplatin, docetaxel and paclitaxel, respectively, with varying concentrations: $0.1,1$ and $10 \mu \mathrm{M}$. After $48 \mathrm{~h}$, cells were treated with MTT as described earlier. Spectrometric absorbance at $490 \mathrm{~nm}$ was measured with a microplate reader. Each group was plated in three wells and repeated three times.

Statistical analysis. SPSS 17.0 software was employed. Data were represented as mean \pm standard deviation (SD). One-way analysis of variance (ANOVA) was used for comparing significance of differences among groups. For all statistical analyses, the level of significance was set as $\mathrm{P}<0.05$.

\section{Results}

Selection of Oct4-GFP stable expression transfectants. In our study, the human Oct4 promoter PCR fragment was confirmed by DNA sequencing and was then inserted into the pEGFP-1 reporter construct upstream of GFP to test the applicability of the expression system. The constructed Oct4-GFP was transfected into human colorectal cancer HT-29 cells. After transfection, GFP was clearly observed in HT-29 cells as shown in Fig. 1A.

Isolation of $\mathrm{GFP}^{+}$cells from the HT-29 cell line. To confirm the above results, the GFP expression levels of selected cells were measured by flow cytometry. As shown in Fig. 1B, the percentage of $\mathrm{GFP}^{+}$cells in HT-29 cell line was $\sim 47.0 \%$. As 

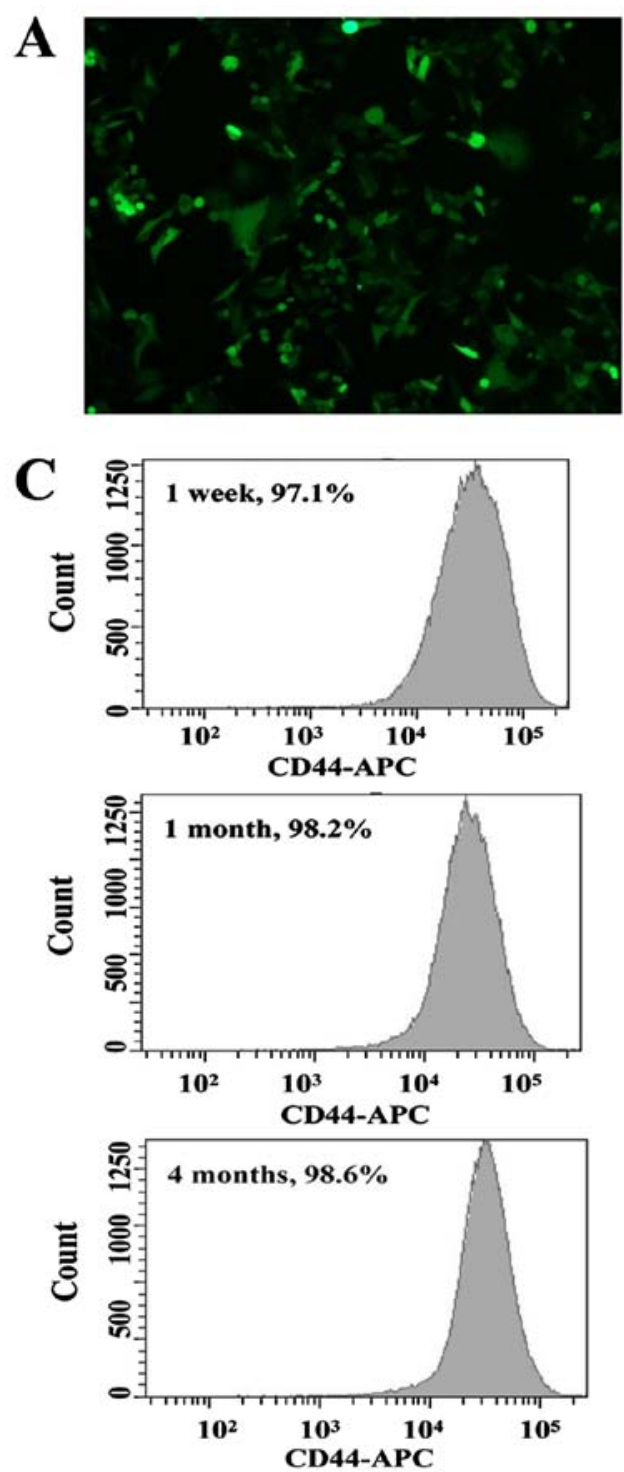

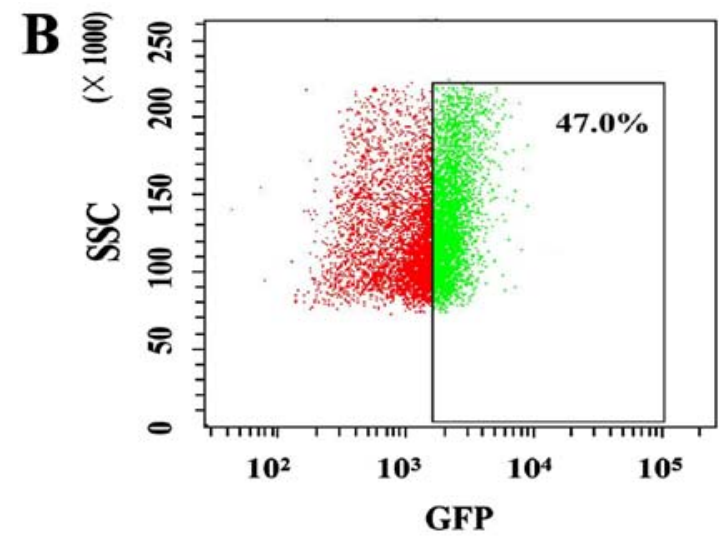

D
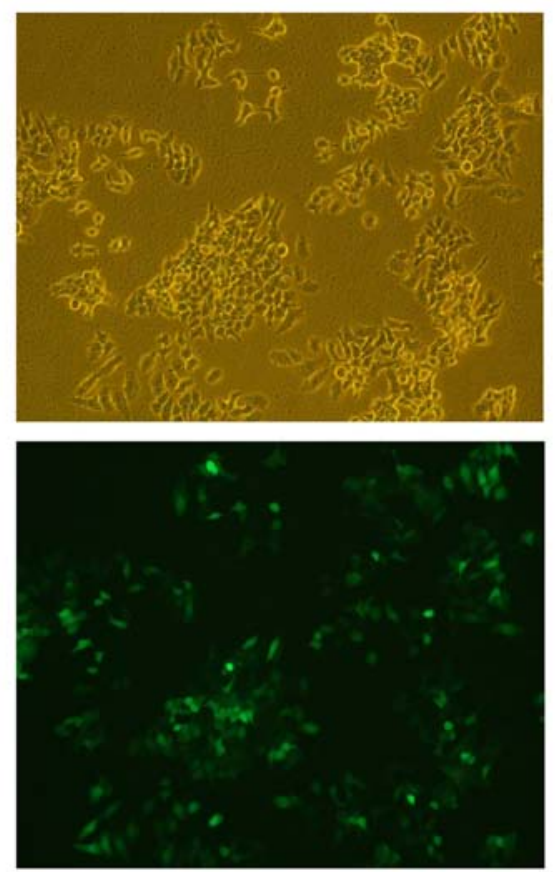

Figure 1. Characterization of Oct4-GFP transfected HT-29 cells. (A) At 6 weeks, the expression of GFP is shown by UV microscopy with the magnification of x200. (B) In the presence of $0.5 \mathrm{mg} / \mathrm{ml} \mathrm{G} 418$ for 6 weeks, the expression levels of GFP were measured with a flow cytometry. (C) Following isolation for 1 week, 1 month and 4 months, the expression of CD44 was measured by flow cytometry. (D) Four months after GFP ${ }^{+}$cells isolated from HT-29 cell line, they were observed with light microscopy and UV microscopy (with the magnification of x200, respectively), suggesting nearly $100 \%$ positivity. SSC, side scatter; GFP, green fluorescent protein; APC, allophycocyanin.

described previously (27), several thousand $\mathrm{GFP}^{+}$cells arising from HT-29 cells were sorted by flow cytometry. These isolated HT-29 cells might possess some characteristics of CSCs as the GFP expression could reflect the Oct 4 promoter expression. Thus, the CSC-like HT-29 cells were chosen for measuring the expression of stem cell marker CD44.

Differentiation of the CSC-like cells can be blocked. Following isolation for 1 week, 1 month and 4 months, we measured the expression levels of CD44 in CSC-like HT-29 cells (Fig. 1C). The stable incorporation of the Oct4-GFP vector seemed to block the differentiation of CSCs. Based on the results shown in Fig. 1D, we found the expression levels of CD44 in isolated CSC-like HT-29 cells were similar and nearly 100\% GFPpositivite. To further explore the relationship between CD147 and CSC-like HT-29 cells, the expression levels of selected biomarkers were measured by flow cytometry. For mono-color fluorescent staining, the expression levels of CD44 and CD147 in CSC-like cells were 99.0 and $96.8 \%$, whereas the expression levels of non-CSCs (NCSCs) were 0.1 and $19.0 \%$, respectively (Fig. 2A and B). For double-color fluorescent staining, the expression level of CD44/CD147 was $95.8 \%$ (Fig. 2C). These results reflected that $\mathrm{CD} 147$ might play a significant role in CSC-like cells.

Specific siRNA inhibits the expression of CD147 in CSC-like HT-29 cells. We used RT-qPCR and western blot analysis to evaluate the knockdown efficiency of CD147 in CSC-like HT-29 cells. $\beta$-actin was regarded as an normalization control. As shown in Fig. 3A, cells infected with Ad-shRNA effectively inhibited CD147 mRNA level $(\mathrm{P}<0.001)$, and there was no significant difference between CSC and Ad-shRNA-control $(\mathrm{P}=0.647)$. In addition, western blot analysis confirmed the downregulation of CD147 protein by Ad-shRNA (Fig. 3B). The 

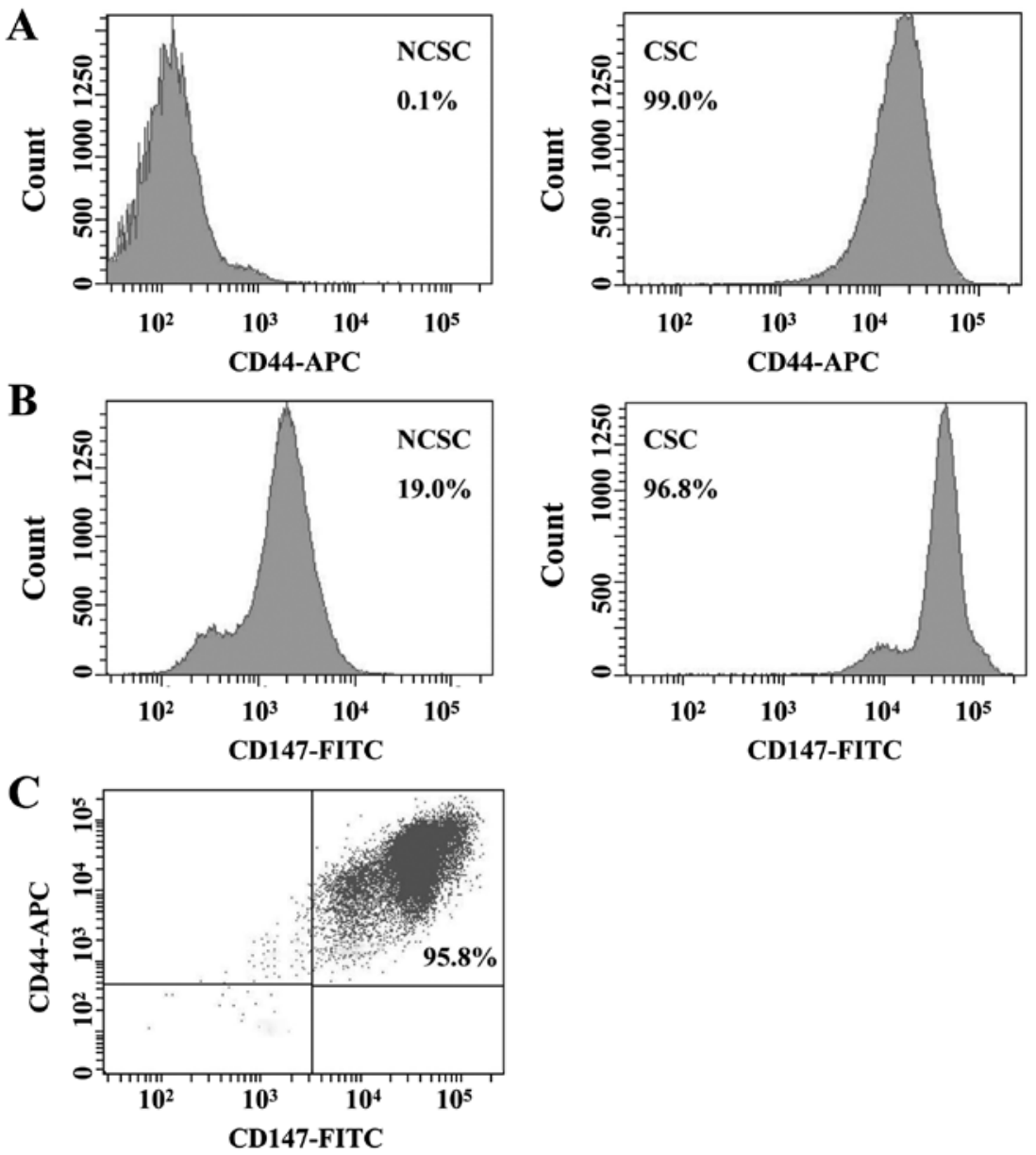

Figure 2. Flow cytometry analysis of CD44 and CD147 expression levels in CSC-like cells and non-CSC-like cells. (A) The expression of CD44 in CSC and NCSC. (B) The expression of CD147 in CSC and NCSC. (C) The expression of both CD44 and CD147 in CSC. APC, allophycocyanin; FITC, fluorescein isothiocyanate. CSC, cancer stem cell; NCSC, non-cancer stem cell.

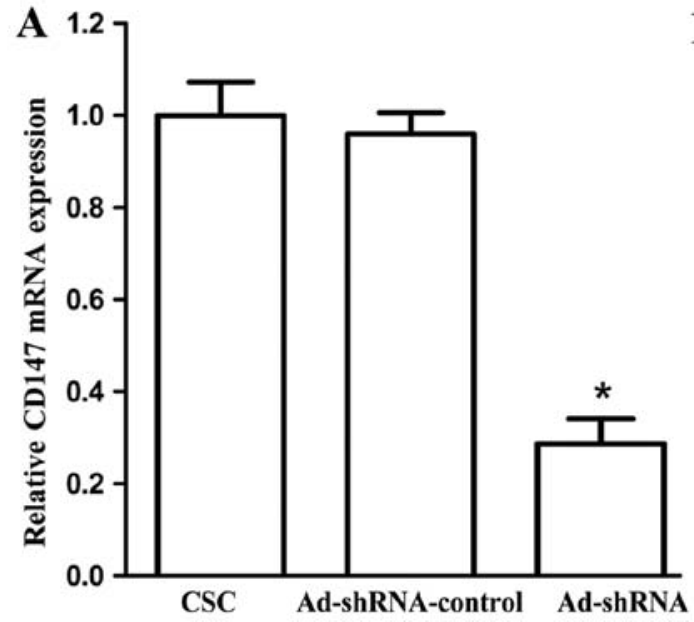

B

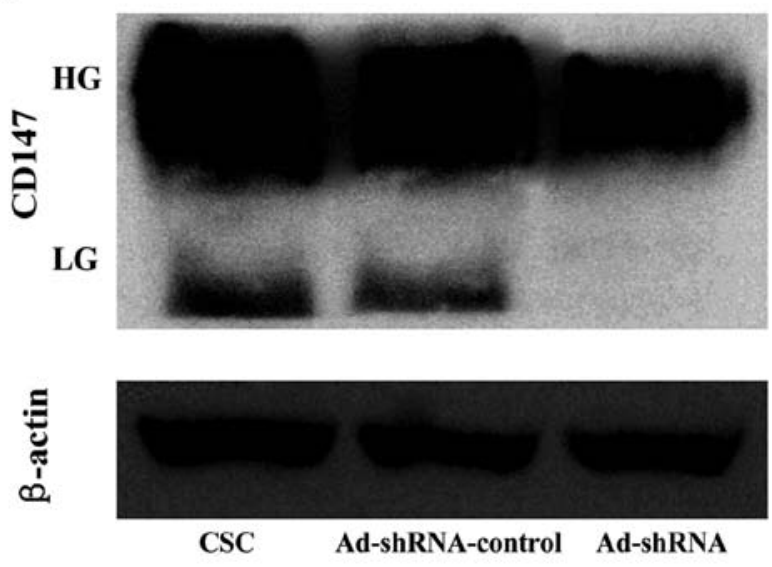

Figure 3. CD147 specific shRNA results in the reduction of CD147 mRNA and protein levels in CSC-like HT-29 cells. Forty-eight hours after infection with Ad-shRNA-control and Ad-shRNA (10 PFU/cell), (A) RT-qPCR analysis of CD147 mRNA expression, $\beta$-actin was used as normalization control, ${ }^{*} \mathrm{P}<0.01$ compared with CSC. The experiments were repeated three times. (B) Western blot analysis of CD147 protein levels, the amount of proteins loaded $(30 \mu \mathrm{g})$ was normalized using $\beta$-actin. HG, high glycosylated form; LG, low glycosylated form. CSC, cancer stem cell; HG, high glycosylated form; LG, low glycosylated form.

lowly glycosylated CD147 (LG-CD147, $33 \mathrm{kDa}$ ) completely disappeared, and the level of highly glycosylated (HG-CD147, $\sim 40-60 \mathrm{kDa}$ ) was diminished.
CD147 silencing reduces the proliferation and invasion of CSC-like HT-29 cells. To examine whether CD147 silencing affects CSCs proliferation, we used MTT assay to determine 

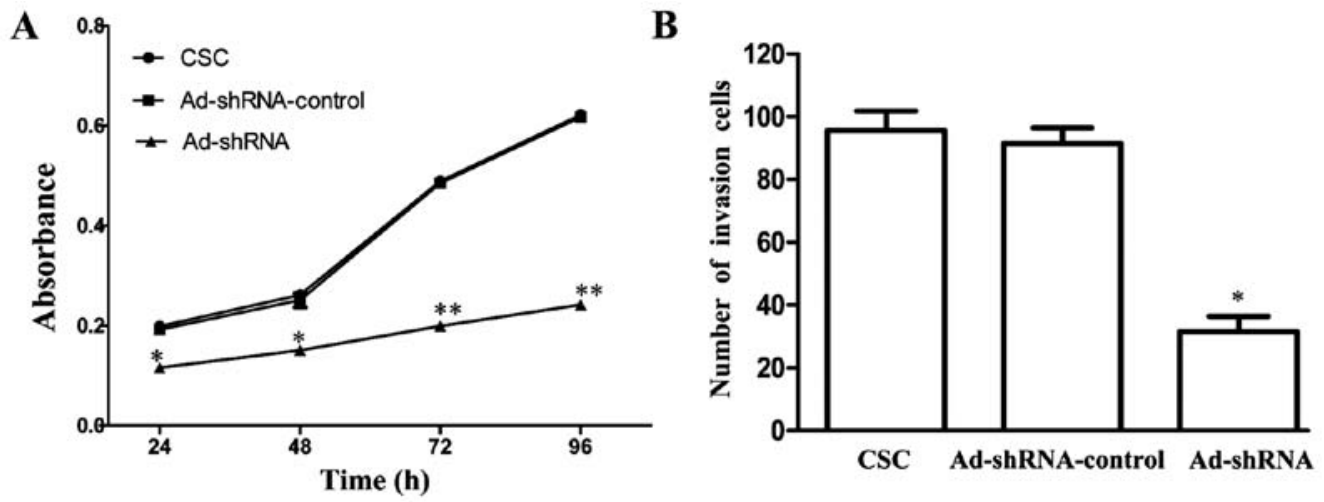

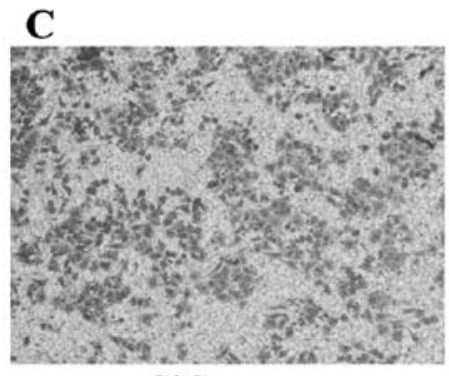

CSC

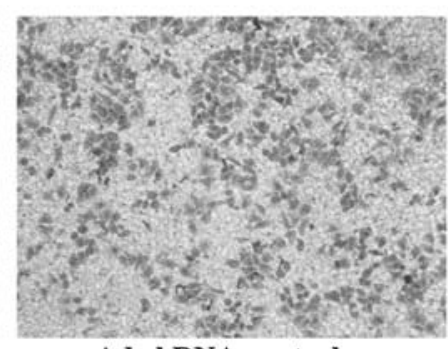

Ad-shRNA-control

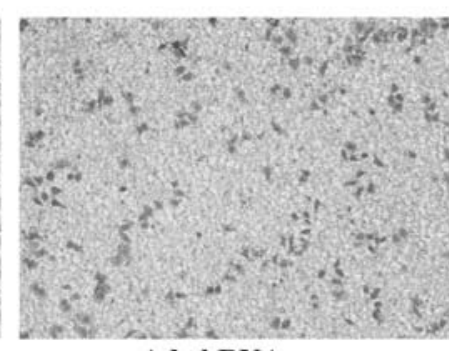

Ad-shRNA

Figure 4. Biological properties of CD147 in CSC-like HT-29 cells. Forty-eight hours after infection with Ad-shRNA-control and Ad-shRNA (10 PFU/cell). (A) The proliferation of CSC-like HT-29 cells was measured by MTT assay. The spectrometrics absorbance at $490 \mathrm{~nm}$ was measured using a microplate reader The experiments were repeated three times, ${ }^{*} \mathrm{P}<0.05,{ }^{* *} \mathrm{P}<0.01$ compared with CSC. (B) The average number of cells from that invaded through the chamber. The data were expressed as mean of five fields, "P<0.01 compared with CSC. The graph was representative of three separate experiments. (C) Representative images of cells reaching to lower surface of the chamber (x200). CSC, cancer stem cell.

A

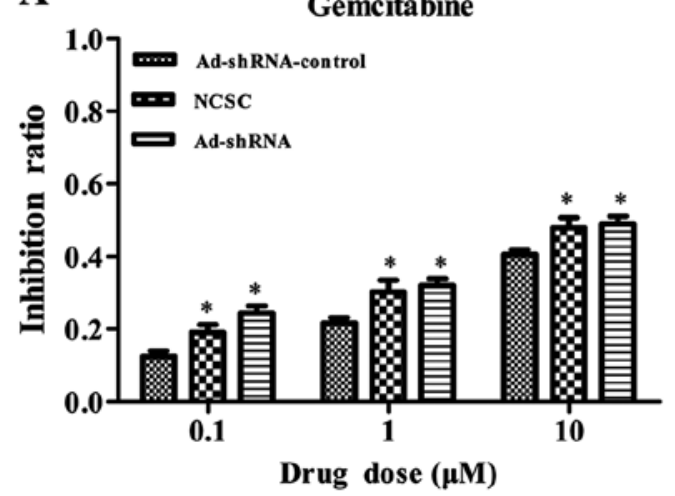

C

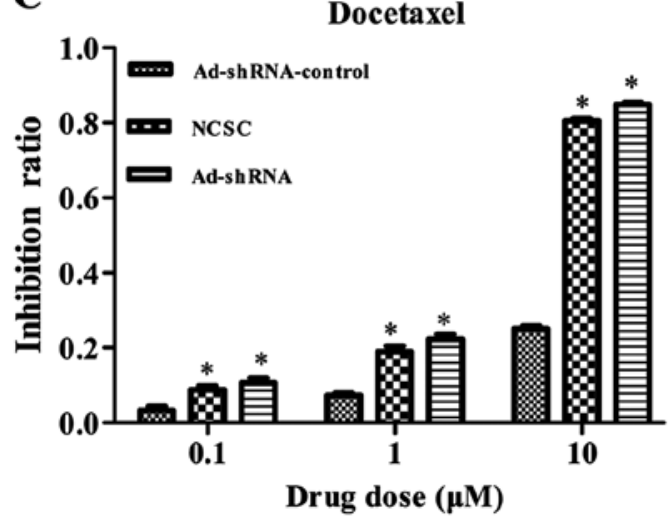

B



D

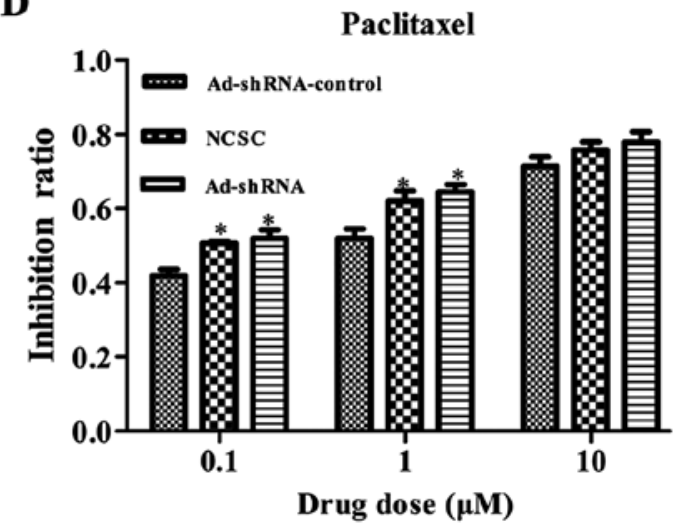

Figure 5. Multidrug chemosensitivity of CSC-like cells after CD147 silencing. Cells were infected with CD147-specific RNA interference at 48 h. All the cells were treated with gemcitabine (A), cisplatin (B), docetaxel (C) and paclitaxel (D) with varying concentrations: $0.1,1$ and $10 \mu \mathrm{M}$ for $48 \mathrm{~h}$. The cell viabilities were measured with MTT assay. The bars represented the SD. ${ }^{*} \mathrm{P}<0.05$ compared to Ad-shRNA-control. Data are representative of three independent experiments. NCSC, non-cancer stem cell. 
the proliferation of CSCs, Ad-shRNA-control and Ad-shRNA, respectively. The data, compared with CSCs, showed that the proliferation of Ad-shRNA was inhibited to $42.4 \%(\mathrm{P}=0.002)$, 43.7\% $(\mathrm{P}=0.002), 59.3 \%(\mathrm{P}<0.001), 61.1 \%(\mathrm{P}<0.001)$ at 24,48 , 72 and 96 h, respectively (Fig. 4A). There was no significant difference between CSC and Ad-shRNA-control ( $\mathrm{P}=0.502$, $0.387,0.624$ and 0.631 , respectively). Furthermore, Matrigel Transwell analysis was used to further assess this effect of CD147 knockdown on invasive ability of CSCs. The number of Ad-shRNA cells passing through the Matrigel was markedly lower than the number of CSCs and Ad-shRNA-control cells, suggesting that the silencing of CD147 significantly inhibited invasion compared with $\mathrm{CSC}(\mathrm{P}=0.001$, Fig. 4B). There was no significant difference between CSC and Ad-shRNA-control $(\mathrm{P}=0.517)$.

CD147 silencing sensitizes CSC-like HT-29 cells to chemotherapeutic drugs. CSCs had been proposed to be more chemoresistant than NCSCs. It had been reported that CD147 expression was overexpressed in multidrug-resistant cells and could confer resistance to some chemotherapeutic drugs. We then investigated whether the downregulation of CD147 in the CSC-like cells, with an RNAi method, could affect the sensitivity to chemotherapeutic drugs. Using MTT assay, we tested the sensitivity of CSC-like HT-29 cells to four drugs. As shown in Fig. 5, shRNA mediated CD147 silencing increased the sensitivity of CSC-like cells to gemcitabine, docetaxel and cisplatin at $0.1,1$ and $10 \mu \mathrm{M}$ (Fig. 5A-C, $\mathrm{P}<0.05$ ). The results show that there was no significant difference among the three groups to paclitaxel at $10 \mu \mathrm{M}$ (Fig. 5D, $\mathrm{P}=0.19$ ).

\section{Discussion}

CSCs play an important role in cancer recurrence and metastasis. These cells are a specific small population that can initiate tumor growth and sustain self-renewal. Previous studies demonstrated that CSCs could resist traditional therapies and were associated with tumor recurrence $(10,11,28)$. CSC-enriched population isolated from colorectal cancer cells may provide new opportunities for targeted identification. As an adhesion molecule, CD147 is widely expressed in a variety of cancer types. Recently, Higashi et al (29) demonstrated that CD147 may be an undifferentiated marker of human embryonic stem cells. Despite substantial progress of CD147 in cancer pathogenesis, the biological roles of CD147 are not clear in CSCs. To the best of our knowledge, this is the first study performed to investigate the biological functions of CD147 in CSC-like HT-29 cells. In the present study, we demonstrated that blocking CD147 expression via RNAi could effectively inhibit CSC-like HT-29 cell proliferation and invasion activity, but increased their chemosensitivity.

Current purification methods generally only enrich CSCs. Ginestier et al and Diehn et al indicated that efficient tumorigenesis requires at least several hundred cells even in highly immunocompromised hosts $(30,31)$. We successfully isolated several thousand $\mathrm{GPF}^{+}$cells from HT-29 cell line as shown in Fig. 1B. The currently used promising detection methods for CSC are based on stem cell-specific biomarkers. Cell surface markers, such as CD24, CD34, CD44, CD90, CD133, aldehyde dehydrogenase (ALDH) and c-Met are generally used to identify CSCs by flow cytometry $(18,19,32,33)$. Of many CSCs markers identified thus far, CD44 is of particular biologic importance (34). Studies have shown that nuclear CD44 directly reprograms stem cell properties in colorectal cancer cells (35). Here, we chose CD44 as a surface marker for $\mathrm{GFP}^{+}$cells. Previously, Sajithlal et al and Kang et al demonstrated that CD44 expression level was high in CSC-like cells (36). We also observed upregulation of CD44 in the CSC-like HT-29 cells. Our flow cytometry results showed much higher expression level of CD147 in CSC-like cells than in NCSCs. Hao et al and Slomiany et al studied CD147 and CD44 expression levels in breast CSCs and found both CD147 and CD44 enriched in CSCs (37-39). Similar results were observed in our studies. Interestingly we found that the expression levels of CD44 in isolated CSC-like HT-29 cells ranged from 1 week to 4 months were similar. However, the specific molecular mechanism of how the Oct4-GFP vector blocks the differentiation of CSC-like cells is still unclear and we will explore it in the future.

Recently, the CSC theory was proposed and attracted much attention of oncologists in the world. It provided a new angle in the research of malignancy and gradually gained significance. Thus, identification of pure colorectal CSCs is the key for targeted therapies. However, enrichment of CSCs remains the challenge in this process (40). In this study, we isolated CSC-like cells from HT-29 cell line to explore possible relevant therapeutic strategies against cancer. Targeting of CSCs might shed light on cancer therapy, however, this goal is challenging as CSCs are resistant to conventional treatments $(10,41)$. Therefore, new therapies based on increased knowledge of CSCs are urgently needed.

shRNA that were processed to form small interfering RNA (siRNA) enabled persistent inhibition of endogenous gene expression (24). Here, we silenced CD147 expression in CSC-like HT-29 cells by CD147-specific siRNA. Using RNAi technology, Yang et al revealed that the inhibition of CD147 expression reduced tumor cell invasion in salivary adenoid cystic carcinoma cell lines (42). It was shown that high level of Cyclophilin A could promote cell proliferation through interactions with CD147 involving activation of ERK1/2 and p38 MAPKs in human pancreatic cancer cells (43). In our study, we detected the proliferation ability changes by MTT assay. The results revealed that $\mathrm{CD} 147$ silencing reduced the proliferation in CSC-like HT-29 cells. Matrigel invasion assay suggested that invasion of Ad-shRNA cells was significantly inhibited. These results indicated that CD147 might play a potential role in promoting proliferation and invasion of CSCs.

Multidrug resistance remains the main cause of treatment failure and mortality in colorectal cancer patients. Traditional therapies aimed at the bulk population of cancer cells in the proliferation and mitotic phases, leading cancer cells into interphase, the main cause of cancer recurrence. Our data demonstrated that CD147 silence increased chemosensitivity to gemcitabine, cisplatin, and docetaxel, but not paclitaxel at $10 \mu \mathrm{M}$, indicating that the expression of CD147 is closely related to drug resistance in CSCs. The results also suggested that the concentration of panclitaxel must be higher than $10 \mu \mathrm{M}$ when used in treatment of colorectal cancer. Studies revealed that CD147 was associated with drug resistance to some other anticancer agents in breast CSCs $(36,37)$. Xu et al found that 
CD147 promoted 5-FU resistance in colorectal cancer (44). The $\mathrm{CD} 44^{+} / \mathrm{CD} 147^{+}$phenotype is a unique property of tumor cells associated with drug resistance in prostate cancer (23). CD44 is a primary receptor for hyaluronan (HA). CD147 was highly expressed in multidrug resistance (MDR) cells and stimulated the production of HA in mammary carcinoma cells leading to induction of MDR in a HA-dependent manner $(45,46)$. These studies suggested that CD147 might play an important role in drug resistance on various types of cancer. Therefore, it might be possible for CD147 to regulate drug-sensitivity of cancer cells.

In conclusion, our results provide some information on colorectal CSCs regarding characteristic features of stem cells and the biological functions of CD147 involved in proliferation, invasion and multidrug resistance properties. By understanding the accurate role of CD147 in the CSCs, we should consider developing treatment based on the CSC model. Based on inhibition of CD147 expression, a novel and promising therapeutic approach may be developed.

\section{Acknowledgements}

This study was supported by grants from The National Natural Science Foundation of China (no. 81472027), Nanjing Science and Technology Committee Project (no. 201108025), Nanjing Medical Science and Technique Development Foundation to Y.Q.P. (nos. QRX11255 and YKK13107) and B.S.H. (no. QRX11254).

\section{References}

1. Wasserman M, Baxter NN, Rosen B, Burnstein M and Halverson AL: Systematic review of internet patient information on colorectal cancer surgery. Dis Colon Rectum 57: 64-69, 2014.

2. Siegel R, Desantis C and Jemal A: Colorectal cancer statistics, 2014. CA Cancer J Clin 64: 104-117, 2014.

3. George S, Wang Q, Heinrich MC, Corless CL, Zhu M, Butrynski JE, Morgan JA, Wagner AJ, Choy E, Tap WD, et al: Efficacy and safety of regorafenib in patients with metastatic and/or unresectable GI stromal tumor after failure of imatinib and sunitinib: A multicenter phase II trial. J Clin Oncol 30 2401-2407, 2012.

4. Vacchelli E, Eggermont A, Galon J, Sautès-Fridman C, Zitvogel L, Kroemer G and Galluzzi L: Trial watch: Monoclonal antibodies in cancer therapy. OncoImmunology 2: e22789, 2013

5. Challen GA and Little MH: A side order of stem cells: The SP phenotype. Stem Cells 24: 3-12, 2006.

6. Jiang W, Peng J, Zhang Y, Cho WC and Jin K: The implications of cancer stem cells for cancer therapy. Int J Mol Sci 13 : 16636-16657, 2012.

7. Clevers H: The cancer stem cell: Premises, promises and challenges. Nat Med 17: 313-319, 2011.

8. Dick JE: Stem cell concepts renew cancer research. Blood 112: 4793-4807, 2008.

9. Ricci-Vitiani L, Lombardi DG, Pilozzi E, Biffoni M, Todaro M, Peschle C and De Maria R: Identification and expansion of human colon cancer-initiating cells. Nature 445: 111-115, 2007.

10. Maugeri-Sacca M, Vigneri P and De Maria R: Cancer stem cells and chemosensitivity. Clin Cancer Res 17: 4942-4947, 2011

11. Irvin DK, Jouanneau E, Duvall G, Zhang XX, Zhai Y, Sarayba D, Seksenyan A, Panwar A, Black KL and Wheeler CJ: T cells enhance stem-like properties and conditional malignancy in gliomas. PLoS One 5: e10974, 2010.

12. Lapidot T, Sirard C, Vormoor J, Murdoch B, Hoang T, CaceresCortes J, Minden M, Paterson B, Caligiuri MA and Dick JE: A cell initiating human acute myeloid leukaemia after transplantation into SCID mice. Nature 367: 645-648, 1994.
13. Awad O, Yustein JT, Shah P, Gul N, Katuri V, O'Neill A, Kong Y, Brown ML, Toretsky JA and Loeb DM: High ALDH activity identifies chemotherapy-resistant Ewing's sarcoma stem cells that retain sensitivity to EWS-FLI1 inhibition. PLoS One 5: e13943, 2010.

14. Cameron SR, Dahler AL, Endo-Munoz LB, Jabbar I, Thomas GP, Leo PJ, Poth K, Rickwood D, Guminski A and Saunders NA: Tumor-initiating activity and tumor morphology of HNSCC is modulated by interactions between clonal variants within the tumor. Lab Invest 90: 1594-1603, 2010.

15. Michishita M, Akiyoshi R, Yoshimura H, Katsumoto $T$, Ichikawa H, Ohkusu-Tsukada K, Nakagawa T, Sasaki N and Takahashi K: Characterization of spheres derived from canine mammary gland adenocarcinoma cell lines. Res Vet Sci 91: 254-260, 2011

16. Smith BH, Gazda LS, Conn BL, Jain K, Asina S, Levine DM, Parker TS, Laramore MA, Martis PC, Vinerean HV, et al: Threedimensional culture of mouse renal carcinoma cells in agarose macrobeads selects for a subpopulation of cells with cancer stem cell or cancer progenitor properties. Cancer Res 71: 716-724, 2011.

17. Overdevest JB, Thomas S, Kristiansen G, Hansel DE, Smith SC and Theodorescu D: CD24 offers a therapeutic target for control of bladder cancer metastasis based on a requirement for lung colonization. Cancer Res 71: 3802-3811, 2011.

18. Tang KH, Dai YD, Tong M, Chan YP, Kwan PS, Fu L, Qin YR, Tsao SW, Lung HL, Lung ML, et al: A CD90(+) tumor-initiating cell population with an aggressive signature and metastatic capacity in esophageal cancer. Cancer Res 73: 2322-2332, 2013.

19. Blacking TM, Waterfall M and Argyle DJ: CD44 is associated with proliferation, rather than a specific cancer stem cell population, in cultured canine cancer cells. Vet Immunol Immunopathol 141: 46-57, 2011.

20. Schöler HR, Ruppert S, Suzuki N, Chowdhury K and Gruss P: New type of POU domain in germ line-specific protein Oct-4. Nature 344: 435-439, 1990.

21. Okumura-Nakanishi S, Saito M, Niwa H and Ishikawa F: Oct-3/4 and Sox 2 regulate Oct-3/4 gene in embryonic stem cells. J Biol Chem 280: 5307-5317, 2005.

22. Biswas C: Tumor cell stimulation of collagenase production by fibroblasts. Biochem Biophys Res Commun 109: 1026-1034, 1982.

23. Hao JL, Cozzi PJ, Khatri A, Power CA and Li Y: CD147/ EMMPRIN and CD44 are potential therapeutic targets for metastatic prostate cancer. Curr Cancer Drug Targets 10: 287-306, 2010.

24. Zou W, Yang H, Hou X, Zhang W, Chen B and Xin X: Inhibition of CD147 gene expression via RNA interference reduces tumor cell invasion, tumorigenicity and increases chemosensitivity to paclitaxel in HO-8910pm cells. Cancer Lett 248: 211-218, 2007.

25. Sidhu SS, Nawroth R, Retz M, Lemjabbar-Alaoui H, Dasari V and Basbaum C: EMMPRIN regulates the canonical Wnt/betacatenin signaling pathway, a potential role in accelerating lung tumorigenesis. Oncogene 29: 4145-4156, 2010.

26. Gerrard L, Zhao D, Clark AJ and Cui W: Stably transfected human embryonic stem cell clones express OCT4-specific green fluorescent protein and maintain self-renewal and pluripotency. Stem Cells 23: 124-133, 2005.

27. Rothermund K, Rogulski K, Fernandes E, Whiting A, Sedivy J, $\mathrm{Pu} \mathrm{L}$ and Prochownik EV: C-Myc-independent restoration of multiple phenotypes by two C-Myc target genes with overlapping functions. Cancer Res 65: 2097-2107, 2005.

28. Tsai KS, Yang SH, Lei YP, Tsai CC, Chen HW, Hsu CY, Chen LL, Wang HW, Miller SA, Chiou SH, et al: Mesenchymal stem cells promote formation of colorectal tumors in mice. Gastroenterology 141: 1046-1056, 2011.

29. Higashi K, Yagi M, Arakawa T, et al: A novel marker for undifferentiated human embryonic stem cells. Monoclon Antib Immunodiagn Immunother 34: 7-11, 2015.

30. Ginestier C, Hur MH, Charafe-Jauffret E, Monville F, Dutcher J, Brown M, Jacquemier J, Viens P, Kleer CG, Liu S, et al: ALDH1 is a marker of normal and malignant human mammary stem cells and a predictor of poor clinical outcome. Cell Stem Cell 1: 555-567, 2007.

31. Diehn M, Cho RW and Clarke MF: Therapeutic implications of the cancer stem cell hypothesis. Semin Radiat Oncol 19: 78-86, 2009.

32. Leal JA and Lleonart ME: MicroRNAs and cancer stem cells: Therapeutic approaches and future perspectives. Cancer Lett 338: 174-183, 2013. 
33. Medema JP: Cancer stem cells: The challenges ahead. Nat Cell Biol 15: 338-344, 2013.

34. Zöller M: CD44: Can a cancer-initiating cell profit from an abundantly expressed molecule? Nat Rev Cancer 11: 254-267, 2011.

35. Su YJ, Lai HM, Chang YW, Chen GY and Lee JL: Direct reprogramming of stem cell properties in colon cancer cells by CD44. EMBO J 30: 3186-3199, 2011.

36. Sajithlal GB, Rothermund K, Zhang F, Dabbs DJ, Latimer JJ, Grant SG and Prochownik EV: Permanently blocked stem cells derived from breast cancer cell lines. Stem Cells 28: 1008-1018, 2010.

37. Kang MJ, Kim HP, Lee KS, Yoo YD, Kwon YT, Kim KM, Kim TY and Yi EC: Proteomic analysis reveals that CD147/ EMMPRIN confers chemoresistance in cancer stem cell-like cells. Proteomics 13: 1714-1725, 2013.

38. Hao J, Chen H, Madigan MC, Cozzi PJ, Beretov J, Xiao W Delprado WJ, Russell PJ and Li Y: Co-expression of CD147 (EMMPRIN), CD44v3-10, MDR1 and monocarboxylate transporters is associated with prostate cancer drug resistance and progression. Br J Cancer 103: 1008-1018, 2010.

39. Slomiany MG, Grass GD, Robertson AD, Yang XY, Maria BL, Beeson C and Toole BP: Hyaluronan, CD44, and emmprin regulate lactate efflux and membrane localization of monocarboxylate transporters in human breast carcinoma cells. Cancer Res 69: 1293-1301, 2009.

40. Kim KM and Yi EC: CD147 is critical for cancer stem cell chemoresistance: what does this mean for the clinic? Expert Rev Proteomics 10: 313-315, 2013.
41. Bartucci M, Svensson S, Romania P, Dattilo R, Patrizii M, Signore M, Navarra S, Lotti F, Biffoni M, Pilozzi E, et al: Therapeutic targeting of Chk1 in NSCLC stem cells during chemotherapy. Cell Death Differ 19: 768-778, 2012.

42. Yang X, Zhang P, Ma Q, Kong L, Li Y, Liu B and Lei D: EMMPRIN contributes to the in vitro invasion of human salivary adenoid cystic carcinoma cells. Oncol Rep 27: 1123$1127,2012$.

43. Li M, Zhai Q, Bharadwaj U, Wang H, Li F, Fisher WE, Chen C and Yao Q: Cyclophilin A is overexpressed in human pancreatic cancer cells and stimulates cell proliferation through CD147. Cancer 106: 2284-2294, 2006.

44. Xu T, Zhou M, Peng L, Kong S, Miao R, Shi Y, Sheng H and Li L: Upregulation of CD147 promotes cell invasion, epithelialto-mesenchymal transition and activates MAPK/ERK signaling pathway in colorectal cancer. Int J Clin Exp Pathol 7: 7432-7441, 2014.

45. Rau KM, Kang HY, Cha TL, Miller SA and Hung MC: The mechanisms and managements of hormone-therapy resistance in breast and prostate cancers. Endocr Relat Cancer 12: 511-532, 2005.

46. Misra S, Ghatak S, Zoltan-Jones A and Toole BP: Regulation of multidrug resistance in cancer cells by hyaluronan. J Biol Chem 278: 25285-25288, 2003. 